\title{
Memória oficial em sala de aula: percepções de alunos do ensino médio e fundamental de Marechal Cândido Rondon-PR sobre patrimônio e bens culturais locais
}

Méri Frotscher ${ }^{1}$

\section{RESUMO}

0 artigo tem como objetivo analisar resultados de pesquisa realizada com alunos da rede pública de ensino de Marechal Cândido Rondon, município situado no Oeste do Paraná, no sentido de perceber: 1) as diferentes noções de patrimônio entre eles existentes; 2) quais bens culturais são considerados significativos para o patrimônio local e sob que razões; 3) a relação entre tais concepções e memórias existentes na e sobre a cidade.

Palavras-chave: patrimônio, preservação, memória, poder, ensino de história, representações sociais

Diversos autores que lidam atualmente com a questão do patrimônio tem apontado para a necessidade de se procurar conhecer a recepção, as percepções e apropriações que cada grupo social faz do patrimônio (CANCLINI, 1994, p. 105), considerando-se as relações entre os sujeitos e os objetos de preservação, na medida em que "o patrimônio cultural não é um dado, mas uma construção que resulta de um processo de atribuição de significados e sentidos" (CHAGAS, 2002, p. 138).

Sob esta preocupação, desenvolveu-se, no segundo semestre de 2004, uma pesquisa em escolas do município de Marechal Cândido Rondon - PR, com 0 objetivo de captar as diferentes noções de patrimônio existentes entre alunos e de perceber quais bens culturais locais são por eles considerados

\footnotetext{
1 Doutora em História Cultural pela UFSC. Professora do Colegiado de História da UNIOESTE - Universidade Estadual do 0este do Paraná, Campus de Marechal Cândido Rondon - PR. E-mail: meri@ rondotec.com.br.
} 
significativos. A pesquisa foi realizada em duas escolas estaduais, o Colégio Estadual Eron Domingues e o Colégio Maximiliano Ceretta, e uma escola particular, a Escola Martin Luther, envolvendo 416 alunos do ensino fundamental ( $5^{a}$ a $8^{a}$ série) e médio.

Com relação à metodologia, optou-se pela realização da enquête sem nenhuma aula introdutória ou maiores esclarecimentos sobre o projeto, uma vez que 0 intuito era realmente fazer com que os alunos respondessem às perguntas de uma forma espontânea. Para evitar a indução de respostas, as perguntas da enquête deveriam ser suficientemente abertas para não influenciar sobremaneira a resposta dos alunos. Pensando nisto, foram formuladas duas perguntas, aplicadas de igual forma em todas as classes visitadas: "0 que é patrimônio para você?"; "Que patrimônio você acha que deveria ser mais valorizado no município?".

\section{Análise dos resultados}

A realização da enquête revelou dificuldades, por parte de muitos alunos, sobretudo os do ensino fundamental ( $5^{\mathrm{a}}$ a $8^{\mathrm{a}}$ séries), em definir o conceito "patrimônio" (107 alunos demonstraram não ter noção do que seja "patrimônio" ou não responderam à primeira pergunta). A maioria destes se encontram entre a $5^{\mathrm{a}}$ e a $8^{\mathrm{a}}$ série do ensino fundamental, muitos dos quais na escola estadual Maximiliano Ceretta, uma das escolas que atende o maior número de crianças carentes do município. A segunda pergunta, em que tiveram que dar exemplos de bens culturais locais por eles considerados significativos, é que possibilitou uma melhor análise do levantamento realizado.

Através dela, percebeu-se que a grande maioria dos alunos associou 0 conceito "patrimônio" ao passado, a "algo que deva ser preservado", daí muitos citarem "bens antigos" como exemplos de patrimônio. Alguns poucos alunos lembraram, seja em suas definições, seja em seus exemplos, bens relacionados a outros tipos de patrimônio que não o histórico, como, por exemplo, o patrimônio natural e religioso, citados por poucos.

Quase todos os bens citados pelos alunos também se referem a patrimônio material. Das 1.079 citações feitas, apenas 59 se referem a partimônio não material, sendo tais referências, contudo, bem genéricas, tais como "costumes e tradições" (42 referências) e "memória do povo" e/ou "colonizadores" (12 referências). 
Com relação às respostas que enfatizaram o patrimônio histórico, o que chama a atenção não é somente a antiguidade dos bens como um critério importante na definição, mas também uma concepção de história que valoriza apenas os fatos "marcantes" e sujeitos sociais considerados "importantes" na história do município.

Esta constatação nos parece se enquadrar a tendências existentes em muitas escolas que confundem história e patrimônio com certo universo de coisas prioritariamente antigas e raras, "reforçando nos alunos imagens de história e patrimônio como espetáculos externos às suas experiências mais próximas", um perigo, na visão de Marcos A. da SILVA (1995, p. 52).

Quase todos os exemplos citados pelos alunos participantes da enquête remetem a bens construídos e/ou elaborados a partir da emancipação política do município, em 1960, ou, no máximo, a partir do final dos anos 40, quando se iniciou o processo de ocupação mais intensa da região. Ou seja, o marco zero da história local, para estes alunos, seria o período de início das atividades da Colonizadora Maripá que, adquirindo terras da Fazenda Britânia, investiu na propaganda, venda e ocupação de lotes. Um dos alunos, por exemplo, assim justifica os bens que elegeu como significativos: "as casas, prédios, objetos, tudo o que contribuiu para a fundação e (que) durante 54 anos faz parte da história de nosso município".

Esta relação entre patrimônio histórico com o processo de constituição oficial do município pode ser encontrada também em outras respostas dadas por alunos, como este, da $7^{a}$ série: "patrimônio histórico são obras construídas na emancipação do município, ou seja, as praças, a prefeitura". Ou seja, todo o passado vivido anteriormente a estes fatos é silenciado e esquecido pelas memórias de grande parte destes alunos. Outro aluno, da mesma série, justifica: "Eu acho que deveria ser mais valorizado o antigo prédio da prefeitura, porque foi lá que foram tomadas as primeiras decisões para o nosso município". Para outro aluno, a prefeitura seria um exemplo de patrimônio local, pois "concentra todo o poder de Rondon" e de lá "comanda todo o município". o prédio da prefeitura é tido, portanto, como o local "legítimo" de exercício do poder decisório no município e como a materialização de uma memória que valoriza as ações dos dirigentes do município ao longo de sua história.

Muito embora a antiguidade seja um dos elementos levantados por 
muitos alunos como um critério importante no estabelecimento do que seria ou não patrimônio, pode-se destacar que a antiga prefeitura (21), um prédio de madeira semi-utilizado situado nas proximidades do novo paço municipal, foi menos citado do que o novo prédio ( 46 vezes). Tal fato pode revelar ou um desconhecimento sobre a existência e localização do antigo prédio e/ou uma valorização maior do atual prédio. A fachada desta construção, toda em vidro e metal, tida como "moderna", contrasta significativamente com o antigo prédio da prefeitura, construído em madeira, material fartamente existente na região, à época. 0 projeto do novo prédio vem ao encontro de discursos presentes na sociedade, que valorizam o "progresso" alcançado pelo município desde a época de sua fundação oficial e a modernização, e que também circulam, como podemos perceber, entre a nova geração de habitantes, no espaço escolar.

As casas de madeira, muitas ainda existentes no espaço urbano do município, são dia-a-dia demolidas, sem parecer despertar a atenção dos moradores. Elas fazem parte de todo um processo de transformações urbanas, levadas a cabo não somente pelo governo municipal, mas pelos moradores, em geral. Demolir construções antigas em madeira e construir outras novas, em alvenaria, talvez possa significar, ainda, a valorização da modernização urbana que teria trazido consigo a melhoria das condições materiais de moradia do proprietário. Sendo assim, na medida em que esta concepção se materializa, sepultam-se marcas de outros tempos, tempos em que a dependência em relação à natureza era maior, fato visível nos próprios materiais utilizados nas casas e nas técnicas de construção.

Certamente uma das formas como ocorreu a ocupação do município, através de um determinado tipo de mão-de-obra migrante, pequenos proprietários oriundos do Oeste de Santa Catarina e Rio Grande do Sul, cuja memória é priorizada nos relatos sobre o passado do município, tenha favorecido a construção de um imaginário que destaca o progresso material havido e, por conseguinte, práticas de apagamento do que não é considerado moderno.

Através da análise da pesquisa realizada, percebe-se ainda uma compreensão conservadora de patrimônio, pautada na memória oficial, e que se reproduz no ambiente escolar. A valorização de um patrimônio institucionalizada pelo poder público e consagrado pela memória oficial aparece em afirmações de alunos que chegam a lamentar o descaso dos moradores 
para com alguns monumentos erigidos em memória a ex-prefeitos, ao lado do Paço Municipal, a chamada "Galeria dos ex-prefeitos", inaugurada no dia 25 de julho de 2000, aniversário da emancipação política do município. Ou seja, além de não se questionar a maneira abusiva com que muitos políticos no Brasil procuram marcar seu nome na paisagem urbana, mesmo que ainda vivos - como é o caso dos ex-prefeitos de Marechal, muitos dos quais presentes à solenidade de inauguração! - alguns alunos lamentam a falta de conservação de tais monumentos.

Alguns dos bustos dos ex-prefeitos, expostos em fileira, encontram-se depredados, em que pese o pouco tempo em que lá se encontram, evidenciando que nem sempre os investimentos oficiais na memória de determinados sujeitos encontra total respaldo entre a população. Apesar disto, muitos dos bens citados pelos alunos são "lugares dá memória" criados e/ou valorizados pela memória das elites locais.

Em diversas respostas se associa patrimônio à estátua de alguma pessoa considerada "importante" no município. Um aluno, quando procura definir patrimônio, faz a seguinte ponderação: "para mim é quando um lugar ou uma estátua tem o nome de uma pessoa que fez alguma coisa pela cidade, que construiu ou criou alguma coisa para melhorá-la".

Em que pese tal compreensão, pode-se perceber que outra parte dos alunos inquiridos associa patrimônio a espaços públicos que prestem serviços à população e/ou que sejam de uso comum. Daí a referência a hospitais, escolas, praças, etc. Muitos alunos mencionaram a própria escola ou as escolas em geral, como um patrimônio do município (107 citações, num total de 1.079), mostrando uma identificação com aquele espaço em que passam uma parte de seu dia. Isso revela como as suas percepções sobre o tema tem muito a ver com a sua própria experiência de vida. Chama a atenção que a valorização da escola enquanto um patrimônio público é mais forte no colégio Eron Domingues. Alguns dos alunos chegam a citar até mesmo a idade da escola, revelando esforços, naquele ambiente, de valorização daquele patrimônio escolar.

0 número de citações a escolas do município só é suplantado pela menção às praças municipais, que foram citadas 109 vezes. Em ambos os

\footnotetext{
Memorial é inaugurado em Marechal Rondon. O Jornal, Marechal Candido Rondon, 23 de abril de 2000, p. 08.
} 
casos, revela-se uma identificação destes alunos com espaços públicos frequientados por eles cotidianamente, no caso da escola, e em momentos de lazer, no caso das praças. Nestes espaços parecem reconhecer sinais de sua identidade, a de aluno e de criança/adolescente, o que nos confirma a constatação de que a cidade é diferentemente apropriada e utilizada pelos grupos sociais, verdadeiros "praticantes dos espaços" que estabelecem com os objetos e lugares diversas relações.

A maior parte das citações das praças se refere à praça central da cidade, denominada Willy Barth, nome do administrador da Colonizadora Maripá. Localizada entre a Prefeitura Municipal e a Igreja Evangélica Luterana, a praça comporta uma área de lazer para crianças e adolescentes, área verde recortada por caminhos para pedestres, um chafariz, uma construção imitando a técnica construtiva do enxaimel, utilizada para venda de artesanato local, que dá frente para uma das avenidas centrais da cidade, que leva o nome da empresa colonizadora. Além disto, encontram-se ali alguns monumentos em memória a personagens da história oficial, como bustos de Marechal Rondon e do próprio Willy Barth, inaugurados em 1965 e dispostos frente a frente, o primeiro homenageado enquanto "sertanista e desbravador do hinterland" brasileiro", e o outro enquanto "benfeitor da colônia e precursor do progresso". Tais referências à idéia de "desbravamento" e "progresso" encontram-se também materializadas no trator esteira utilizado na abertura das estradas e transformado em monumento, em 1983, quando foi exposto a céu aberto na mesma praça, sob a seguinte manchete de jomal: "um símbolo de progresso". A placa que the identifica faz menção às "primeiras estradas do município", abertas através da Companhia Maripá, atualizando o discurso do pioneirismo tão presente na memória oficial da cidade.

0 terceiro bem mais citado pelos alunos foi uma casa particular de propriedade do alemão Heribert Gasa, que imigrou para o Brasil no início da década de 1960, instalando-se no município e vindo a falecer recentemente. 0 número de citações a este imóvel (89) supera o número de todos os demais imóveis com fins residenciais citados (77, se contarmos entre eles os citados sob a denominação de "construções antigas"). 0 número supera, inclusive a soma dos números relativos aos prédios antigo e atual da prefeitura municipal.

0 material empregado e a arquitetura da residência chamam a atenção, pelo contraste que revelam em relação aos demais imóveis da cidade. Construído 
num lote de esquina, a uma quadra das duas principais avenidas do município, parte de uma das fachadas do imóvel lembra a técnica construtiva denominada enxaimel, por conta do madeiramento à vista. A parede próxima à porta de entrada da residência é feita de tijolos maciços, dispostos de diferentes formas. Outra parte desta fachada, também construída com tijolos à vista, sem recuo em relação à calçada, apresenta larga porta que dá acesso a um porão, atualmente alugado para fins comerciais.

A fachada lateral do prédio, com largo recuo em relação à calçada, é construída em tijolos maciços, sem telhado à vista, dando um ar pesado à construção, mesmo dispondo de janelas, porém pequenas e com vidros escuros coloridos. Tal aparência maciça e as características externas de sua construção fazem o prédio destoar do seu entorno. 0 interior do imóvel, que ainda hoje serve de residência à herdeira, mistura uma série de materiais, cores, estilos e desenhos. Segundo Heribert Gasa, em entrevista sobre o assunto, a casa é uma "miscelânea de culturas. Há traços gregos, germânicos, italianos, astecas, entre outros", fato que lhe teria trazido, há anos atrás, "incômodo", por conta de "interpretação errônea de algumas figuras" da casa (Revista Circus apud STEIN, 2002, p. 60).

Esta residência, construída nos anos 60 , em que a maioria da população construía suas residências com madeira extraída na própria região, deve ter também chamado a atenção dos moradores naquela época, a maioria dedicados à agricultura.

Nas respostas dos alunos, percebe-se um imaginário, também presente entre moradores do município, que envolve o imóvel e seu antigo morador num ar de mistério. Num dos questionários, um aluno chega a fazer referência a um túnel secreto que existiria debaixo do imóvel. Outro aluno assim afirma: "a casa demorou 20 anos para ser construída e tem várias passagens secretas".

Noutros questionários, faz-se menção a esta residência e a de outro imigrante alemão, a de Friedrich Seyboth (total de 10 referências), como residências de alemães que teriam se instalado em Marechal Cândido Rondon "fugidos" da guerra, chegando-se a afirmar, numa das respostas, que as casas de ambos teriam servido de "abrigo para muitos refugiados". Mesmo que tais informações não tenham sido até hoje comprovadas, além do equívoco de associarem a sua vinda ao Brasil com o final da Segunda Guerra Mundial, 
mesmo tendo esta ocorrido pelo menos quinze anos antes de sua imigração, tais discursos circulam pela cidade e se fazem perceber nas enquêtes realizadas.

A idéia do extraordinário, justificada pela aparência da casa, é acentuada pelas estórias que se contam acerca do seu morador. Em resposta à pergunta sobre que patrimônio deveria ser mais preservado no município, um aluno escreve: "a casa do Sr. Gasa, por seus mistérios e estórias ainda não reveladas..." Se buscarmos compreender melhor a trajetória deste morador no município, percebe-se que alguns elementos, reelaborados, tornaram-se subsídio para se criar este imaginário social que envolve a sua casa e o seu morador numa aura de mistério.

Corria 0 ano de 1967, quando um agente do DOPS de Curitiba, numa investigação pelo estado do Paraná, vai divulgar o município de Marechal Cândido Rondon como uma "colônia de nazistas", um "IV Reich", por conta da presença de alguns ex-combatentes da Segunda Guerra Mundial, entre eles Heribert Hans-Joachim Gasa. 0 agente do DOPS, um judeu austríaco que havia emigrado em 1939, para a Argentina, e ali havia colaborado para os Países Aliados, acreditava estarem escondidos em Marechal Cândido Rondon criminosos de guerra como Joseph Mengele e Martin Borman.

Estas denúncias, publicadas em jornais nacionais e internacionais, em que pese os protestos de moradores e políticos da região (STEIN, 2002, p. 5362), voltaram a ser citadas em décadas posteriores, em livros e periódicos do exterior, realimentando o fato criado em 1967. Segundo Marcos Stein, um dos aspectos que teria levantado naquela data as suspeitas de Gasa ter sido um "agente nazista" foi a forma como edificou sua residência, o que levou 0 investigador do DOPS a concluir que o porão da casa se tratava de um esconderijo para fugitivos nazistas. Segundo o mesmo autor, estes discursos encontraram sustentação na mídia, mesmo sem encontrarem sustentação.

Considerando tais fatos, pergunta-se: 0 que leva crianças e adolescentes a considerar a casa de Gasa como um bem importante a ser preservado? Justo a casa que fez Marechal Cândido Rondon internacionalmente conhecida como o "IV Reich no Brasil"?

0 que se percebe é que a desinformação, uma percepção da residência pautada por uma aura de mistério e uma concepção conservadora, que valoriza o extraordinário, e ao mesmo tempo turístico-mercadológica de patrimônio, contribuíram para que o imóvel e seu construtor, de alvo de suspeição e 
denúncia, de repente desponte como bem e personagem a serem valorizados e mesmo alvo de projeto visando, respectivamente, sua museificação e reabilitação/ qualificação. As dificuldades de acesso a informações e documentos atinentes à época em que Gasa e Seyboth viveram na Europa, sobretudo à década de 30 até o fim da Segunda Guerra, se existentes, assim como um profundo desconhecimento em relação à própria história européia, por parte da maioria dos habitantes do município, contribui para isto.

0 fato destas residências serem tidas como extraordinárias ainda pode ser entendido pelo fato de seus proprietários terem vindo do exterior e sido excombatentes no maior conflito mundial, algo sui generis para muitos moradores. 0 fato destes e de alguns outros ex-combatentes na Segunda Guerra Mundial terem se instalado no município e imediações tem sido veiculado através de algumas reportagens da imprensa local, em alguns momentos, como curiosidades locais.

Este tipo de concepção de patrimônio, que focaliza o extraordinário e que é marcada por ações preservacionistas isoladas, geralmente tendo como foco os bens e a memória de alguém em particular, pautou durante muito tempo ações e intervenções do próprio IPHAN, anteriormente SPHAN, na sociedade brasileira. No caso da casa em questão, parece que esta noção se perpetua no município, em que pesem as mudanças de concepção do patrimônio havidas nos últimos anos e que tem resultado, inclusive, em políticas e ações que levem em conta o patrimônio popular e o patrimônio imaterial, ou seja, não mais apenas o patrimônio em "pedra e cal" das elites e de instituições públicas.

Apesar disto, tem-se implementado no Brasil e noutras partes do mundo, projetos e práticas preservacionistas pautadas num paradigma político-cultural mercantilista, através do qual se realizam gastos para a preservação do patrimônio como uma forma de angariar dividendos para o mercado imobiliário ou ao turismo (CANCLINI, 1994, p. 104). Tais iniciativas muitas vezes são tomadas por interesses privados, associados ao poder público e entidades da sociedade civil, como é o caso do projeto de revitalização da casa de Gasa, visando transformá-la em memorial. Em reportagem dada à revista Região, em 2005, revela-se a "intenção de que a casa se transforme em um dos principais pontos de visitação do roteiro de turismo integrado da Costa Oeste, servindo como atrativo histórico-cultural a partir de julho de 2006". 3

3 Muitas histórias. Revista Região, Marechal Candido Rondon, ano VI, n. 56, 2005, p. $28-29$. 
Este projeto é fruto de parceria entre a viúva de Heribert Gasa, do Conselho de Desenvolvimento dos Município Lindeiros ao Lago de Itaipu, Sebrae, Prefeitura de Marechal Cândido Rondon, Acimacar e ainda alguns professores da própria universidade (Unioeste).

Tal visão mercantilista de patrimônio cultural, associada a interesses dos mais diversos, são possibilitadas por políticas e projetos de preservação elaborados por agentes culturais e ligados ao turismo, muitas vezes contratados especialmente para este fim, visando facilitar a captação de recursos, sem se democratizar a discussão sobre patrimônio na cidade, possibilitando-se o direito a outras memórias. Nestor Canclini adverte para o fato de que "a seleção do que se preserva e a maneira de fazêlo devem ser decididas através de um processo democrático em que os interessados intervenham" (CANCLINI, 1994, p. 105).

0 projeto do Memorial Gasa visa não somente preservar a casa e o acervo do falecido morador, como investir numa positivação de sua própria imagem, na medida em que se objetiva, por um lado, "desmistificar a fantasia em torno da vida do imigrante" e "mostrar o lado do pioneiro, do primeiro ótico e fotógrafo de Marechal Cândido Rondon". ${ }^{4}$ Ou seja, a tentativa de legitimação do projeto passa inclusive por uma proposta de reescrita da história pessoal do morador, muito embora seja extremamente difícil reconstituir sua trajetória na Alemanha. Além disto, o projeto pretende incorporar a memória e o patrimônio particular deste emigrante alemão instalado em General Rondon, no início dos anos 60, a uma memória da cidade que tem insistido em valorizar 0 "pioneirismo" de alguns de seus moradores.

Lidar com o patrimônio requer cuidados e um exercício contínuo de reflexão e problematização sobre o processo de construção da memória, uma vez que práticas de preservação e/ou destruição de bens culturais não se dão fora das relações de poder entre pessoas e grupos que disputam poderes no espaço da cidade. Jacques Le Goff, ao discutir sobre as relações entre memória e história e sobre o papel do historiador, já advertia: "cabe ao historiador não fazer o papel de ingênuo", ao lidar com a memória (LE GOFF, 1996, p. 548).

É certo que há a necessidade dos moradores de uma cidade garantir às gerações futuras, o direito de gozar da herança de seus ascendentes, de preservar

\footnotetext{
4 Idem, p. 28.
} 
e proteger o seu patrimônio como uma forma de se desenvolver a auto-estima dos grupos que compõem a cidade. Para tanto, há que se problematizar, contudo, qual patrimônio se está querendo preservar, de quem é este patrimônio, qual sua significação para os moradores da cidade, quem está promovendo sua valorização, sob que interesses e meios, etc. 0 problema mais desafiante ao se lidar com patrimônio, segundo Nestor Canclini, é analisar os usos que são dados aos bens históricos, daí a necessidade de se colocar às políticas culturais que tratam do patrimônio, algumas perguntas, tais como:
a) com que ótica são restaurados? (...)
b) de que modo se apresentam e se explicam os edifícios antigos ao serem abertos ao público? (...)
c) apenas a catalogação e a restauração fazem parte da política cultural ou também se procura conhecer as necessidades e os códigos do público? 0 que acontece na recepção e apropriação que cada grupo faz da história?" (CANCLINI, 1994, p. 105).

Para outro autor, Jérome MONNET, crítica em relação às ações em defesa do patrimônio, o problema da proteção "é saber quem controla esses processos em uma cidade (...) Na escala de uma sociedade, trata-se de identificar as alianças de interesses que geram, nas palavras e nos atos, o 'discurso dominante' que serve de matriz para as representações sociais, para a cultura comum e fornece as justificativas para a ação ou para a inatividade" (MONNET, 1996, pp. 222-223).

Considerando que não somente Gasa, mas também outros moradores, como Seyboth, foram alvo de suspeição e denúncia por parte do DOPS, em 1967, e que a residência e hospital construídos pelo último ainda existem no município, é de se questionar, ainda, o porquê da casa de Seyboth não ter sido tão citada quando a do Gasa, entre os alunos. Aí que se percebe o papel da imprensa na difusão de determinadas imasgens, já que em alguns momentos divulgou-se as intenções em se transformar a sua residência em museu. Percebese, portanto, um forte papel da mídia na argumentação a favor de implementação de práticas de preservação lideradas ou encampadas pelo poder público municipal, juntamente com outras entidades e pessoas interessadas e na divulgação de tal bem enquanto um bem importante a ser preservado. 
Não é de se esquecer a influência de toda uma política implementada pela prefeitura do município, visando desenvolver o turismo, através da Oktoberfest e da estilização arquitetônica, a partir dos anos 80, na tentativa de se compreender a valorização de determinadas edificações. Em 1986, a Secretaria de Indústria e Comércio elaborou o "Projeto de Caracterização Germânica do Município", elegendo o enxaimel e a "casa dos Alpes" como modelos construtivos a serem incentivados no município, concedendo isenção do pagamento do IPTU àqueles que construíssem prédios com tais características (STEIN, 2003). A partir de então, diversas fachadas de prédios, tanto públicos, como de particulares, foram construídos imitando tais técnicas e formas, contribuindo para uma maquiagem do espaço urbano, com 0 objetivo de the conferir determinada identidade.

0 enxaimel, técnica construtiva trazida da Europa e utilizada no século XIX e início do século XX no Sul do Brasil, em que a estrutura do prédio é de madeira, sendo o resto das paredes preenchido com taipa, tijolos ou pedras, acabou sendo divulgado erroneamente nas últimas décadas como "arquitetura alemã" ou "estilo germânico". Nos últimos anos, por conta de políticas de incentivo ao turismo cultural, muitos municípios no Sul do país tem incentivado a imitação desta técnica, através da simples aplicação de sarrafos de madeira na fachada de prédios públicos e privados. Este também foi o caso de Marechal Cândido Rondon, onde tal técnica nem fez parte das experiências construtivas locais, em sua história, tendo em vista o caráter mais recente de sua ocupação e a abundancia de madeira para construção de imóveis.

Tais práticas de maquiagem urbana e uma imagem que associa Marechal Cândido Rondon à germanidade podem também ter contribuído para que os alunos fizessem referências a residências construídas por dois imigrantes alemães. Isto fica evidente na resposta de uma aluna, ao justificar a escolha das casas de Gasa e Seyboth como bens a serem mais valorizados no município: "por serem em 'estilo germânico', assim como o Centro de Eventos". Neste caso, a aluna associa duas residências construídas por estrangeiros para fins particulares e uma construção que já nasce com a função de servir como monumento, ${ }^{5}$ o Centro de Eventos, com 0 objetivo de materializar o que chama de "origens européias" de parte de seus moradores. Esta afirmação revela não somente equívocos, pois faz entender que

\footnotetext{
5 Françoise CHOAY distingue "monumentos" de "monumentos históricos". Segundo tal distinção, o monumento é uma criação deliberada, cuja destinação foi pensada a priori. 0 monumento histórico, por sua vez, não é, desde o princípio, desejado e criado como tal, é construído a posteriori. (CHOAY, 2001).
} 
enxaimel seria um estilo, e não uma técnica construtiva, e um estilo "germânico", muito embora tal técnica seja encontrada noutros países europeus, assim como uma visão estimatizante, ao identificar tais imóveis construídos por alemães como "tipicamente germânicos".

Percebe-se, portanto, como o discurso oficial e as práticas que 0 acompanharam, desde os anos 80, visando dar uma imagem ao município, foram absorvidos por muitos moradores e, por conseguinte, seus filhos, atualmente alunos das escolas. É o que fica visível na resposta de um aluno, e que permeia a resposta de outros: "Quando se fala em Marechal Cândido Rondon, a primeira coisa que se lembra é que é uma cidade de alemão, então o que se deve preservar é o estilo germânico das construções e dos primeiros habitantes, isso que forma a identidade de Rondon".

Ao se demonstrar os artifícios utilizados pela mídia e pela municipalidade, no sentido de produzir uma determinada imagem para o município, não se deixa de perceber que muitas destas representações circulam entre os moradores da cidade, até porque elas não são veiculadas num chão totalmente impróprio. É no chão fértil e previamente preparado que as representações se firmam e são consideradas "verdadeiras". Segundo Michel de Certeau, os discursos de representação procuram fazer crer que se está falando em nome do "real", possibilitando desta forma a sua circularidade. Se o fim de todo discurso é fazer com que os corpos "soletrem uma ordem", (CERTEAU, 1994, pp. 240-241) parece que o discurso que identifica Marechal Cândido Rondon com a germanidade encontrou um campo propício nas escolas, como visto.

Entende-se que também por conta da política de maquiagem da cidade, a partir dos anos 80, que o Centro de Eventos do município tenha sido também bastante referenciado pelos alunos. Este pavilhão de eventos, inaugurado há poucos anos, reproduz partes frontais de prédios antigos europeus, em suas quatro fachadas, como se fosse um cenário a céu aberto. Neste caso, não se transformou algo existente em monumento, como é o caso do que se pretende realizar com a casa de Heribert Gasa, mas se construiu algo, tijolo por tijolo, para já servir como monumento. Esta réplica de fachadas tem o intuito de fixar uma memória que confira uma identidade européia ao município, por conta da insistência em se valorizar a idéia de "origem", no caso, alemã, de parte da população.

Tal prática de maquiagem do espaço urbano não é novidade de Marechal Cândido Rondon, mas muito corrente nas últimas duas décadas em cidades que 
investem no turismo no Sul do país. Não à toa, anualmente, no interior daquelas fachadas ocas, que se realizam a festa do município, em 25 de julho (a festa do Boi no Rolete), e a Oktoberfest, os maiores eventos turísticos do município.

Não se trata aqui de discutir se tal construção é autêntica ou inautêntica, mas de perceber o aspecto da "recriação", prática que tem se tornado comum na contemporaneidade, possibilitada pela reprodutibilidade técnica do passado. Reginaldo Gonçalves nos adverte para a necessidade de considerarmos a idéia de uma forma "não-aurática" de autenticidade, ou seja, o caráter construído ou tecnicamente reproduzido dos patrimônios culturais, que muitas vezes são associados a idéias de identidade e memória nacional, no nosso caso, à idéia de identidade local (GONCALVES, 1988, pp. 268-269). É o caso do Centro de Eventos, do Portal do Município e de outras construções existentes em Marechal Cândido Rondon, que foram construídas já com o intuito de servir a um projeto de afirmação de uma determinada identidade ao município. No caso do Centro de eventos, não à toa que ali se realizam as duas principais festas do município, a Oktoberfest e a Festa do Boi no Rolete, através das quais se procura produzir e reproduzir determinadas imagens do município.

Se por um lado é uma construção muito recente, ela procura reinventar um passado longínquo para a cidade, intenção visível, por exemplo, nos números que aparecem numa das fachadas do centro de eventos, representando o ano de 1567. Ou seja, se por um lado há no município uma valorização da modernização, esta não exclui práticas e discursos que vão investir na construção de elos com um passado longínquo, que se passa no continente europeu, construindo-se a idéia de ligação entre dois espaços tão distantes geograficamente, mas que seriam tão próximos.

No caso do Centro de Eventos e de outros bens citados, percebe-se, ainda, como bens muito recentes, às vezes construídos há poucos anos, são valorizados enquanto patrimônio local pelos alunos participantes da enquête, por conta daquilo que simbolicamente representariam. Tal constatação revela a força dos investimentos do poder público e da mídia na transformação de algumas construções que imitam fachadas de construções européias e o enxaimel em "cartões-postais" do município, como é o caso do Centro de Eventos e do Portal de entrada do município, inaugurado há poucos anos.

Fato comum a municípios de instalação recente, no interior do Brasil, 
são discursos de valorização da modernização e da idéia do "progresso". Talvez por isto que, numa das respostas, um aluno chega ao limite de tal constatação: dá com exemplo de patrimônio a ser preservado, "o lago que está sendo construído" (!). Apesar da força do argumento estar mais centrada no fato de que tal lugar é um espaço público destinado ao lazer, fica a impressão de que os próprios frutos da própria modernização seriam algo a ser valorizado.

Concluindo, entende-se que, ao se lidar com a questão patrimonial, deve-se problematizar o próprio conceito de preservação. Se por muito tempo as ações patrimoniais no Brasil se pautaram por uma ótica que valorizava a conservação do que era considerado antigo, muitas vezes "congelando" tais bens, na medida em que estes eram isolados e protegidos das transformações do tempo, atualmente percebe-se a necessidade de se conceber o patrimônio e sua preservação relacionando-os com as necessidades globais da sociedade. Além disto, deve-se levar em conta a recepção e as apropriações destes bens culturais, assim como as necessidades e os códigos do público.

Isto não deve significar que, no caso de muitos habitantes terem interiorizado valores dos grupos dominantes, citando bens produzidos e valorizados por tais grupos como dignos de serem preservados, como é o caso de muitos alunos participantes da enquête, que não se deva problematizar suas posições e se realizar trabalhos de educação patrimonial, no sentido de fazer com que os alunos percebam a importância de se alargar o conceito de patrimônio cultural das crianças e adolescentes e fazê-los reconhecer e valorizar a memória do cidadão comum e bens culturais de segmentos marginalizados da população.

Esta proposta, portanto, está imbuída de um sentido políico, na medida em que, através de experiências educacionais participativas, se estenda o direito à memória à população, que passa a valorizar elementos de sua cultura enquanto integrante do patrimônio local e a reivindicar que suas memórias também façam parte da memória da cidade.

\section{Referências}

CANCLINI, Nestor Garcia. 0 patrimônio cultural e a construção imaginária do nacional. Cidade: Revista do Patrimônio Histórico e Artístico Nacional, Brasília - Instituto do Patrimônio Histórico e Artístico Nacional, n. 23, 1994. 
CHAGAS, Mário. Cultura, patrimônio e memória. Integrar: Primeiro Congresso Internacional de Arquivos, Bibliotecas, Centros de Documentação e Museus: textos. São Paulo: Imprensa Oficial do Estado, 2002, p. 135-150.

CHOAY, Françoise. A alegoria do patrimônio. São Paulo: Estação Liberdade/Ed. Unesp, 2001.

GONÇALVES, José Reginaldo. Autenticidade, memória e ideologias nacionais: o problema dos patrimônios culturais. Estudos Históricos, Rio de Janeiro, v. 1, n. 2, 1988, p. 264-275.

GRUNBERG, Evelina. Educação patrimonial: utilização dos bens culturais como recursos educacionais. Cadernos do CEOM, Chapecó, ano 14, n. 12, jun. 2000, p. 159-180.

LE GOFF, Jacques Le. História e Memória. 4ª . Ed. Campinas: Editora da UNICAMP, 1996.

MONNET, Jérome. 0 álibi do patrimônio: crise da cidade, gestão urbana e nostalgia do passado. Revista do Patrimônio Histórico e Artístico Nacional, Brasília, n. 24, 1996, p. 220-228

Muitas histórias. Revista Região, Marechal Cândido Rondon, ano VI, n. 56, 2005, p. 28-29.

SILVA, Marcos A. da. Patrimônios históricos. In: História: o prazer em ensino e pesquisa. São Paulo: Brasiliense, 1995, p. 39-60.

STEIN, Marcos Nestor; FELIPETTO, Vanessa. Identidade e representação: arquitetura "germânica" em Marechal Cândido Rondon - PR. 2003. Texto inédito.

STEIN, Marcos Nestor. Imigração alemã e repressão policial: a ação do DOPS em Marechal Cândido Rondon. Esboços: Revista do Programa de Pós-Graduação em História da UFSC, Chapecó: UFSC, p. 53-62, 2002.

\section{Agradecimentos}

$\mathrm{Na}$ aplicação dos questionários, colaboraram a professora Judite Schmidt, do Colégio Eron Domingues e Escola Martin Luther, e os discentes Jehmy Walendorf, Luciano Palagano e Priscila Marins Marchini, participantes do projeto "Patrimônio Histórico em Marechal Cândido Rondon: levantamento de imóveis, documentação, catalogação de dados e educação patrimonial", por mim coordenado, os quais agradecemos. 


\section{Official memory in the classroom: perceptions of pupils from Marechal Cândido Rondon - PR about heritage and local cultural properties}

ABSTRACT

This article aims to analize the results of a research with pupils of public schools in Marechal Cândido Rondon, West Paraná, to have knowledge of: 1) the different concepts of heritage they have; 2 ) what cultural properties are considered as significative for the local heritage and for what reasons; 3 ) the relation between these concepts and the memories existent in and about the town.

Key words: heritage, preservation, memory, governmental influence, history teaching, social representations. 